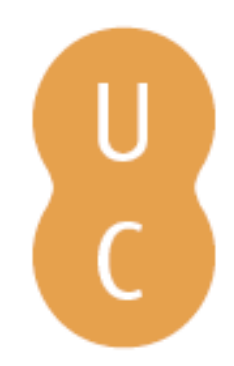

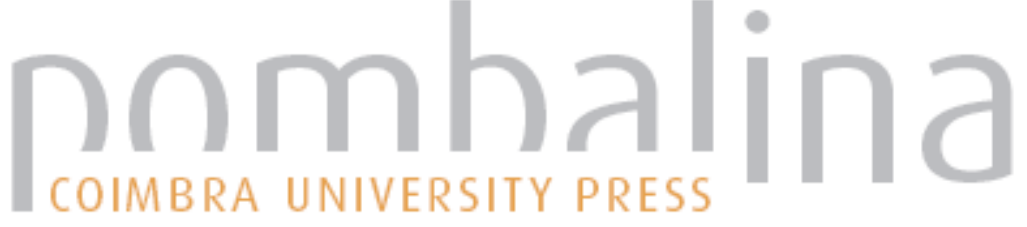

\section{A narrativa da desconfiança na política: a figuração do político}

Autor(es): $\quad$ Peixinho, Ana Teresa; Araújo, Bruno

Publicado por: Imprensa da Universidade de Coimbra

URL

persistente: URI:http://hdl.handle.net/10316.2/41350

DOI: $\quad$ DOl:https://doi.org/10.14195/978-989-26-1324-6_9

Accessed : $\quad$ 26-Apr-2023 16:21:31

A navegação consulta e descarregamento dos títulos inseridos nas Bibliotecas Digitais UC Digitalis, UC Pombalina e UC Impactum, pressupõem a aceitação plena e sem reservas dos Termos e Condições de Uso destas Bibliotecas Digitais, disponíveis em https://digitalis.uc.pt/pt-pt/termos.

Conforme exposto nos referidos Termos e Condições de Uso, o descarregamento de títulos de acesso restrito requer uma licença válida de autorização devendo o utilizador aceder ao(s) documento(s) a partir de um endereço de IP da instituição detentora da supramencionada licença.

Ao utilizador é apenas permitido o descarregamento para uso pessoal, pelo que o emprego do(s) título(s) descarregado(s) para outro fim, designadamente comercial, carece de autorização do respetivo autor ou editor da obra.

Na medida em que todas as obras da UC Digitalis se encontram protegidas pelo Código do Direito de Autor e Direitos Conexos e demais legislação aplicável, toda a cópia, parcial ou total, deste documento, nos casos em que é legalmente admitida, deverá conter ou fazer-se acompanhar por este aviso.

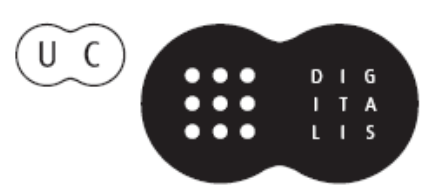





\title{
A NARRATIVA DA DESCONFIANÇA NA POLÍTICA: A FIGURAÇÃo do POLÍtíco
}

\author{
Ana Teresa Peixinho \\ Universidade de Coimbra / CEIS2O \\ Bruno Araújo \\ Universidade de Brasília / CEIS2O
}

\section{A personagem mediática}

No seu mais recente romance - Número Zero - Umberto Eco constrói uma ficção à volta do mundo do jornalismo, apontando, em jeito de caricatura, os piores vícios da imprensa no final do século XX. Numa das cenas que representa uma reunião de redação, o diretor do novo jornal Amanhã propõe que se construa uma reportagem sobre um magistrado italiano incomodativo ao status quo, procurando evidenciar os seus piores vícios e as falhas mais evidentes. Tratavase, portanto, de denegrir uma reputação:

Vejam bem que, hoje, para rebater uma acusação, não é necessário provar o contrário, basta deslegitimar o acusador. Portanto, eis o nome e o apelido do fulano, e Palatino dá um salto a Rimini, com um gravador e uma máquina fotográfica. 
Siga este servidor integérrimo do Estado, ninguém é jamais integérrimo a cem por cento, talvez não seja pedófilo, não terá assassinado a avó, não meteu ao bolso luvas, mas terá feito qualquer coisa de estranho. Ou, então, se me permitem a expressão, estranhifique-se o que faz todos os dias. (Eco, 2015: 99).

Tratava-se de pôr o jornalismo ao serviço da calúnia e da intriga política, construindo um imagem suficientemente duvidosa acerca de uma figura pública, para que o leitor, pelas inferências possibilitadas pelo texto, pudesse colar a pessoa em causa a um cenário de desconfiança e de duvidosa credibilidade, nem que para tal se tivesse de contornar os princípios mais básicos da deontologia profissional.

O que este episódio caricatural romanesco evidencia é um dos aspetos mais sensíveis da vida pública hodierna: a construção das imagens dos homens públicos feita essencialmente pelos media. Sabe-se que esta questão é hoje cuidadosamente trabalhada por poderosas máquinas de comunicação que, conscientes do valor da figuração mediática, cuidam cirurgicamente das informações que devem transpirar para os meios de comunicação acerca de políticos, desportistas e vedetas. Desde a forma de vestir, aos hábitos quotidianos, passando pelos costumes, crenças, fragmentos discursivos, tudo é trabalhado por forma a construir uma figura que encaixe num determinado modelo tido como o ideal.

Aquilo a que o público tem acesso acerca das figuras públicas e o conhecimento que possui sobre essas pessoas raramente é direto ou pessoal. Os atores sociais que povoam os diferentes media, quer em formatos noticiosos quer em produtos de entretenimento, decorrem de construções que mimetizam pessoas reais, com existência ontológica, pouco coincidindo, na maior parte dos casos, com os homólogos reais. Enquanto, nos mundos possíveis da narrativa 
ficcional, as personagens, mesmo quando inspiradas em pessoas, não têm obrigatoriamente de se fixar a essa imagem do mundo ontológico, no caso específico das narrativas ditas "naturais", como as jornalísticas, é indispensável essa correspondência ${ }^{101}$.

Quando as diversas figuras que povoam o nosso universo social - como é o caso de políticos de que aqui se fala - deslizam para as narrativas mediáticas, sejam elas ficcionais ou não, adquirem o estatuto de personagens, perdem a dimensão humana e complexa que ontologicamente possuem, para se verem reduzidas a uma soma de traços identificadores, submetidas a procedimentos retórico-textuais de figuração, que compõem os seus perfis, muitas vezes esquemáticos e incompletos, a partir dos quais os leitores ou espectadores formarão a sua opinião. Como alerta Marc Lits, a atividade de construir personagens pelos media é de uma enorme responsabilidade, pois, na maioria dos casos, são eles as únicas fontes de conhecimento que o público tem ao seu dispor (Lits, 2008). O mesmo é dizer que, quando falamos em pessoa / ator social e personagem mediática estamos, na verdade, a falar de duas entidades distintas, mesmo quando essa personagem integra narrativas com dever de referencialidade ${ }^{102}$. E essa construção é, não raras vezes, sobretudo quando se trata de homens da política, elaborada a partir de um tecido discursivo complexo em que se combinam a influência dos sofisticados assessores de imagem da comunicação política, a capacidade de triagem e de crítica do próprio jornalista, os discursos que se disseminam pelas redes sociais etc. O produto final, que chega ao público, é já o resultado de composições intersubjetivas,

\footnotetext{
${ }^{101}$ Explica Valles Calatrava: "La diferencia fundamental de estos relatos informativos (...) estriba fundamentalmente en su carencia de dimensión ficcional y máxima referencialidad y mimetismo con respecto a la realidad." (Calatrava, 2008: 21).

${ }^{102}$ Comenta Marc Lits, a respeito de figuras como as de Barack Obama ou Bill Clintton: “(..) il faut cependant admettre que la quasi-totalité des téléspectateurs et lecteurs de journaux ne découvrent ces deux personnes, éminemment médiatisées, que par les récits de presse qui les présentent à l'attention de l'opinion (...) Et ceux-ci construisent un personnage selon les critères de vraisembilité, souvent suggérés par les services de communication des hommes politiques en questions." (Lits, 2008: 144).
} 
dialógicas e altamente profissionalizadas. Porém, como bem assinala Mário Mesquita, "quando está em causa a "narrativa factual" (...) o problema não está em demonstrar que as coincidências com a "pessoa real" são fortuitas, mas que, pelo contrário, a personagem coincide, nos seus traços principais, com a pessoa "retratada"" (Mesquita, 2003: 132).

Não se trata aqui de ler à luz de critérios ontológicos de verdade ou falsidade os discursos ficcionais mediáticos, como é o caso daquele que será objeto de análise neste artigo, mas de perceber que a figuração é sempre uma atividade de mediação, que implica uma construção específica, feita quer em função de códigos societais, quer no respeito pelos códigos de género discursivo ou textual. Mesmo no caso das personagens jornalísticas, não se trata de pôr em causa a base factual das narrativas ou de enveredar por um discurso de suspeição que entende que aquilo que os media produzem é, regra geral, manipulação e distorção da realidade. Pelo contrário, deve perspetivar-se o discurso mediático, e dentro dele o jornalístico, precisamente pela sua essencialidade de discurso, só traduzível em textos, que são sempre uma construção semiótica de mediação, um processo de semantização do real, pelo qual os públicos acedem aos acontecimentos. Assumindo um indiscutível papel de mediação, os discursos dos media organizam os conhecimentos, permitem a troca de experiências, através da produção e reprodução de formas simbólicas, configuram a prática social e ditam, se não o como, pelo menos aquilo em que pensamos, moldando os nossos critérios de relevância. ${ }^{103}$

Neste sentido, o contributo dos estudos narrativos para o estudo dos media é absolutamente vital, pois são eles quem poderá fornecer as ferramentas analíticas e o quadro epistemológico de estudo do modo como os media funcionam como instâncias de sentido,

\footnotetext{
${ }^{103}$ A este respeito, João Carlos Correia explica que os media "ganharam uma dimensão importantíssima no que respeita ao estabelecimento de um significado comum e intersubjetivo acerca da vida quotidiana", adiantando que "esta influência se exerce sobretudo ao nível da relevância relativa aos temas em debate" (Correia, s/d: 9).
} 
nomeadamente na construção de personagens: "ser um repórter que lida com factos e ser um contador de 'estórias' que produz contos não são atividades contraditórias", afirma Gay Tuchman (1993: 259). A semantização operada pelos media e o modo como atribuem significados ao real exigem que estes recorram precisamente à narrativa como seu modo estruturante e, dentro dela, se privilegie a personagem como categoria central. Diremos, com G. Vattimo, que "os mass media assumem um papel determinante na sociedade pós-moderna", inscrevendo "a sociedade da comunicação num sistema de efabulação do mundo" (Vattimo, 1990: 13) e que essa efabulação é mediada pela intrínseca narratividade do mediático. Na verdade, os media são hoje uma das grandes fábricas de mitos contemporâneos, como já Roland Barthes demonstrara nas suas Mitologias ${ }^{104}$. Se, à partida, a narrativa deve mediar a realidade de uma maneira objetivada, ela exige um olhar crítico que consiga captar a sua essencialidade construída: não é um lugar de pura e simples reconstituição de factos, fingidos ou "reais", e quer as ações, quer as personagens que as protagonizam são sempre sujeitas a procedimentos de figuração e de construção ${ }^{105}$.

A personagem é uma categoria narrativa que tem estimulado, na última década, uma quantidade considerável de estudos de áreas muito diversas, da Psicologia às Ciências Cognitivas, da Literatura aos Media Studies. Longe vai o tempo em que se circunscrevia ao âmbito da literatura, como bem o assinalam Carlos Reis e Ana Cristina Macário Lopes: "Categoria fundamental da narrativa, a personagem

\footnotetext{
${ }^{104}$ Vejamos o que, mais recentemente, diz Marc Lits a este respeito: "Une étude détaillée des pages régionales des quotidiens permet d'observer comment les journalistes "mythifient" les sujets qu'ils traitent (...) Le fait même d'être mentionné dans un journal rend un personnage ou un événement, de banal et quotidien, mythique". (Lits, 2008: 21)

${ }^{105}$ Seguimos, assim, a hipótese avançada por autores como Phillipe Marion (Marion, 1997) ou Marc Lits (Lits, 2000), para quem o polo mediático, central no sistema social, se constrói segundo uma lógica narrativa, quer na sua produção, quer na sua receção: "Ainsi, le modèle narratif, dans le système médiatique, et tout particulièrement en télévision, contaminerait, médiagéniquement, l'ensemble du dispositif, de telle sorte qu'il est majoritairement construit et consommé sur le mode narratif" (Lits, 2000: 5).
} 
evidencia a sua relevância em relatos de diversa inserção sociocultural e de variados suportes expressivos" (Reis e Lopes, 2003: 314) ${ }^{106}$. A transdisciplinaridade que a afeta diz bem das suas potencialidades semântico-pragmáticas e ideológicas, na construção das narrativas que tecem a nossa identidade social. Num texto recente, $\mathrm{H}$. Heidbrink (Heidbrink, 2010: 67-110) salienta três aspetos importantes na abordagem ao estudo da personagem em contexto não ficcional: i) a relação entre persona e personagem; ii) a ténue fronteira entre real e ficcional; iii) e o facto de a personagem ser sempre uma construção semiótica, feixe de signos complexos e materialmente detetáveis, produto de procedimentos retóricos específicos. Se, na ficção, estas constatações decorrem do estatuto ficcional dos mundos possíveis criados pelo discurso, na narrativa de imprensa, ancorada que está a um pacto comunicacional de "veracidade" e de honestidade factual, já a questão merece outras explicações e adquire outros contornos.

$\mathrm{Na}$ verdade, qualquer estudo que se debruce sobre a figuração da personagem mediática deve contemplar, como já assinalado por alguns autores, o processo simplificador a que são sujeitos os atores sociais no interior das narrativas. Como Mesquita (2002) explica, a respeito da personagem jornalística, há uma clara tendência para a construção de personagens planas ${ }^{107}$, facto que se explica pela conjugação de alguns fatores que afetam a produção noticiosa: por um lado, a urgência de atualidade - que dita a velocidade de produção; por outro lado, a necessidade de adaptação dos discursos a

\footnotetext{
106 A partir da década de 90 do século passado, assiste-se à "ressurreição" desta categoria narrativa, em parte fruto de uma vasta revisão conceptual, operada no quadro de Estudos Narrativos progressivamente mais abrangentes, interdisciplinares e atentos à evolução das narrativas contemporâneas. Disso são testemunho os estudos narrativos cognitivistas, o incremento de investigações sobre a construção social de identidades, os media studies, os estudos culturais, entre outras atuais correntes de pensamento das ciências sociais e humanas.

107 "De acordo com E. M. Forster, responsável pela designação que aqui se adota, as personagens planas "são construídas em torno de uma única ideia ou qualidade: quando nelas existe mais de um fator, atinge-se o início da curva que leva à personagem redonda" (Forster)" (Reis e Lopes, 2003: 322).
} 
um público massificado e heterogéneo - o que impõe a eficácia narrativa em detrimento do aprofundamento das questões. Acresce a estes fatores a ténue fronteira entre o ficcional e o factual, que confere à personagem mediática um cariz complexo e ambíguo: se ela deve um respeito ontológico à figura factual que representa, também se afirma sempre por processos de construção, que envolvem um conjunto de procedimentos retórico-discursivos comuns à narrativa ficcional. Afirma Helen Fulton que "real individuals who form part of news stories therefore have their characters constituted from the sam kinds of discursive material as fictional characters" (Fulton, 2005: 237). Esta duplicidade é, na opinião de Ralf Schneider, absolutamente vital para se captar a essência da personagem, que vive na confluência de um conjunto de informações textuais e do papel proativo da leitura, processo dinâmico fundamentado em modelos cognitivos, sociocognitivos e emotivos (Shneider, 2001: 608).

Os recentes desenvolvimentos dos Estudos Narrativos cognitivos carrearam uma diferente compreensão do funcionamento e do valor da personagem mediática, partindo precisamente da sua natureza paradoxal: se, por um lado, ela é baseada em pessoas reais, por outro lado, é inquestionável que ela resulta de um processo de construção, em que intervêm signos e códigos mais ou menos complexos. O discurso mediático, ao construir figuras, está a propor quadros de leitura, molduras aos leitores e espectadores, a partir dos quais será compreendida a história e as suas personagens. Estas são geralmente associadas a atributos sociais, pessoais e a ações funcionais que levam à rápida identificação e, muitas vezes, à estereotipia.

Assim, no quadro da análise que aqui se propõe - que incidirá sobre a construção do protagonista de um filme - parece relevante chamar a atenção para um conjunto de procedimentos retóricos e narrativos que devem ser considerados na compreensão da construção da personagem do político no quadro de um filme satírico, com claros propósitos caricaturais. 


\section{O político como personagem nos media}

A passagem do século XIX para o XX, argumenta Paul Ricoeur (1965), foi marcada pela propagação de uma "hermenêutica da suspeição", surgida, em grande medida, graças às ideias disseminadas nas obras de Marx, Nietzsche e Freud. Por detrás dessa conceção está o entendimento de que todo discurso pretende ocultar interesses aos quais serve. Ainda que o filósofo estivesse a referir-se a um momento histórico bastante específico, o seu pensamento adquire hoje grande atualidade. De facto, um movimento de generalização da desconfiança como valor universal, particularmente associado ao universo da política, parece constituir parte do modus vivendi dos nossos dias. Variados fatores podem ser apontados como explicativos de tal fenómeno ${ }^{108}$, mas o objetivo central desta reflexão é, perspetivando os media como instâncias produtoras de sentido, compreender o papel que eles desempenham nesse contexto.

Com efeito, a mimetização mediática do político é presidida por um conjunto de signos culturais altamente complexos que participam a montante e a jusante do processo de semantização do mundo levado a cabo no desempenho mediático. Por isso, compreender o político como personagem nos e dos media exige problematizar outros elementos, que se juntam aos procedimentos retórico-narrativos a que fizemos referência anteriormente.

Entendemos, nesse sentido, que, no processo de construção da personagem, os media recorrem a uma gramática cultural, socialmente

\footnotetext{
${ }^{108}$ Não são novos os esforços para compreender os motivos da crise de confiança nas instituições políticas. Desde os anos 1970, uma corrente de pensadores conservadores, nos Estados Unidos da América, partiu da noção de crise democrática - em parte devido aos problemas de governabilidade inerentes à democracia, do ponto de vista desses autores - como fator que explicaria essa descrença. Mais recentes, contudo, são os esforços para analisar o papel que os meios de comunicação aí desempenham. Em diálogo com vários estudos da ciência política, Luis Felipe Miguel (2008) sistematiza três hipóteses explicativas do declínio da confiança nas instituições políticas: (i) a hipótese do cinismo crescente do público; (ii) a hipótese do fim das ilusões e (iii) a hipótese da perceção popular correta continuada. Em cada uma delas, os media exercem papel preponderante.
} 
partilhada, sobre as práticas políticas. Situada no plano da metanarrativa, como diria Motta (2013), essa espécie de ethos prévio sobre a política e os políticos é o que pode explicar, em grande medida, a forma como a figuração da personagem é desenvolvida nos media e a maneira pela qual é percebida pelo público. Em outras palavras, ao construir o político como personagem, os media tendem a incorporar valores constitutivos do imaginário cultural popular que estariam na base da configuração de abordagens estereotipadas sobre a política, como as que observaremos adiante na análise de uma narrativa cinematográfica sobre a vida de um político brasileiro em campanha eleitoral. No Brasil, como em qualquer outro contexto, não se pode compreender a fabricação do político nos media sem levar em consideração a forma como está estruturada a cultura política nacional. E sem perder de vista que essa mesma cultura, que nada mais é que o conjunto de valores e crenças com os quais os cidadãos interagem simbolicamente com a política, vê-se reforçada nas narrativas mediáticas com grande regularidade, tanto nas informativas quanto nas ficcionais.

Sobre a constituição da cultura política brasileira, os estudos de José Álvaro Moisés (1992) a respeito do processo de democratização do país fornecem importantes pistas de análise para o objetivo deste artigo de compreender o modo de figuração do político nos media $^{109}$. Recorrendo a sondagens realizadas no Brasil e em outros

${ }^{109}$ A ideia de cultura política aqui empregada provém dos estudos de Moisés, que a define como um consenso normativo mínimo sobre a democracia e as práticas políticas e inclui [...] "entre outras coisas, a generalização de um conjunto de valores, orientações e atitudes políticas entre os diferentes segmentos em que se divide o mercado político e resulta tanto dos processos de socialização, como a experiência política concreta dos membros da comunidade política" (Moisés, 1992: 7). Ora, para entendermos com maior clareza os valores presentes na cultura política brasileira é fundamental levar em consideração esses "processos de socialização", bem como "a experiência concreta" dos brasileiros com a política, no último século, particularmente no período pós 1988 , que marca a redemocratização do país. Dois exemplos que marcam esses dois fatores constitutivos da cultura política: o primeiro presidente depois da ditadura, José Sarney, não foi eleito diretamente, e Fernando Collor de Melo, o primeiro presidente realmente eleito pelo voto popular, sofreu um processo de impeachment por denúncias de corrupção, dois anos depois de ter ganhado a eleição como o "caçador de Marajás", ou seja, como aquele que lutaria contra os privilégios da classe dominante. 
países latino-americanos sobre a forma como as pessoas veem a democracia, o autor conclui que ainda vigoram, na mente dos cidadãos, conceções autoritárias e clientelistas, como as que caracterizaram parte da vida política do país durante considerável período de sua história, no Império e na República.

Não é mero acaso que, durante as recentes manifestações contra o governo da presidente Dilma Rousseff, pequenos grupos ecoem palavras de ordem pedindo o retorno dos militares ao poder. É fundamental recordar que até a redemocratização, no final dos anos 1980, os brasileiros mantiveram contacto com a democracia apenas entre os anos 1945 e 1964, isto é, entre o fim do Estado Novo e o Golpe Militar que impôs ao país uma ditatura de duas décadas. Antes disso, a república fora proclamada também por meio de um golpe e, nos anos 1930, Getúlio Vargas comandou uma ditadura de cariz populista. Esse processo histórico, portanto, não pode ser olvidado no âmbito de uma reflexão que procura compreender como os media constroem o político como personagem no interior de suas narrativas.

A cultura política brasileira também é marcada por uma forte personificação da atividade política e por um sentimento de desconfiança contínua em relação ao poder - dois valores que, atrelados aos demais, dariam tom ao delineamento das relações entre cidadãos, políticos, instituições e o próprio regime democrático ${ }^{110}$. No que ao primeiro valor respeita, há, de facto, no Brasil como em outros países, uma tónica na figura individual do político, naquilo que ele diz ou faz, nos aspectos mais interessantes da sua biografia,

\footnotetext{
${ }^{110} \mathrm{~A}$ propósito, no VI Congresso de Pesquisadores em Comunicação e Política, na cidade do Rio de Janeiro, Wilson Gomes (2015) identificou um paradoxo curioso: como compreender os elevados índices de desconfiança nas instituições políticas brasileiras, se o Brasil vive hoje o período mais duradouro de estabilidade democrática da sua história?
} 
vistos como grandes estratégias de imagem pelos profissionais do marketing político ${ }^{111}$.

No que ao primeiro valor respeita, há, no Brasil, uma tônica muita acentuada na figura individual do político, e menos no partido político a que pertence. Trata-se de uma espécie de culto à personalidade, naturalmente com menos intensidade do que aquele que se observa num país vizinho como a Argentina, que possui mesmo uma ideologia chamada de peronismo, em referência a Juan Domingo Perón, ex-presidente do país, fundador, em 1946, do Partido Justicialista de la Republica Argentina, da ex-presidente Cristina Fernandéz de Kirchner. No Brasil, a paixão pela dimensão individual do político é visível, nos media, na recorrente importância dada a aspectos triviais e personalistas de sua vida, que aparecem estrategicamente ao lado de declarações do político ou são narradas em episódios que envolvem a sua atuação profissional.

Do ponto de vista da comunicação política, o valor da personalidade é igualmente muito explorado, mas como estratégia de promoção de imagem. Aqui, o destaque a aspectos biográficos que façam com que o público se identifique com o político, além de uma composição que o coloca sempre como guardião da moralidade e da decência no manejo da coisa pública são apenas dois dos exemplos mais emblemáticos do modo como a personalidade figura como valor essencial na cultura política brasileira. Não é por acaso que a narrativa que analisaremos a seguir se estrutura em torno da vida pública e privada de um político-candidato à Presidência da República.

Relativamente ao valor da desconfiança, os brasileiros parecem confiar cada vez menos nas instituições políticas da democracia, como deixam perceber os resultados do Índice de Confiança Social 2015 - pesquisa realizada pelo Instituto IBOPE Inteligência, com

\footnotetext{
${ }^{111}$ Em outro estudo, constatamos que o valor da personificação da vida política aparece com força ainda maior na cobertura jornalística de casos de corrupção política (Araújo; Jorge, 2015).
} 
base numa amostra de 2.000 entrevistas — , segundo os quais instituições, atores políticos e processos eleitorais aparecem como os maiores alvos da desconfiança pública: numa escala de 0 (menor confiança) a 100 (maior confiança), as eleições e os sistema político recebem 33 pontos; a Presidente da República e o Congresso Nacional, 22; e os Partidos Políticos, em último lugar, aparecem com 17 pontos. Instituições fora do espectro político institucional, ao revés, são as que mais merecem a confiança da população, segundo o estudo: o primeiro lugar é ocupado pelo Corpo de Bombeiros, que recebem 81 pontos, seguidos pela Igreja, 71, e as Forças Armadas, com 63 pontos.

Interessante é observar, nesse sentido, a forma como esses valores predominantes na cultura política brasileira - mormente o valor da desconfiança na política, central nesta reflexão - são tecidos como fios narrativos constituidores da imagem do político nas narrativas mediáticas. Num artigo já clássico entre os estudiosos da personagem mediática, Mário Mesquita chama a atenção para o facto de os media frequentemente apostarem na criação de personagens planas com forte tendência para a tipificação e, portanto, para a estereotipia. De acordo ele, o resultado desse processo é a construção de "uma mimesis rudimentar que facilita os efeitos de identificação na medida em que reduz a complexidade dos seres retratados" (Mesquita, 2002: 126).

É de notar que o autor dialoga diretamente com o conceito de estereótipo - incluído no campo das ciências sociais pelas mãos de Walter Lippmann, em Public Opinion (1922) - que nos parece fundamental para compreender o processo de construção do político como personagem. Com efeito, um dos aspectos mais importantes da noção de estereótipo é a ideia de que ele essencializa e reduz a complexidade de uma realidade. Em uma conferência sobre os perigos da história única, a escritora nigeriana Chimamanda Adichie (2009) recorda que o estereótipo nem sempre revela mentiras, mas 
sempre oculta verdades ${ }^{112}$. Salientamos novamente que não interessa pensarmos em termos de verdade/mentira; ao contrário, importa chamar a atenção para o caráter reducionista e descaracterizador da complexidade humana e social presente nos processos de estereotipia, instaurados durante a figuração de certas personagens, nomeadamente as de tipo político, como a que a seguir analisaremos.

Não é, portanto, despropositado afirmar que a figuração do político nos media é realizada por meio de um processo de estereotipia que integra uma lógica mediática hegemônica de construção de mensagens e sentidos, articulada no âmbito de uma teia discursiva complexa, cuja constituição se dá por fatores de ordem sociocultural e por dialogias estabelecidas entre os diferentes agentes discursivos, jornalistas, fontes, leitores etc. Como acima explicitado, a simplificação e a superficialidade que presidem à mimetização de agentes públicos, com existência ontológica, no discurso mediático, constituem as bases para o funcionamento desse processo de estereotipia poderoso, possuidor de efeitos ideológicos muito claros ante o público: a figura do político, como representação de uma categoria indispensável às democracias liberais de cariz representativo, emerge envolta em pré-conceitos, ou seja, numa série de valores negativos previamente estabelecidos - um ethos prévio, como antes se disse - e constitutivos da cultura política nacional.

Destaque-se, todavia, que os media nem sempre atuam na fabricação direta dos estereótipos associados à política; estes são, porém, absorvidos, proliferados e tendem a ser naturalizados no espaço público por meio e em função do discurso daqueles. Com efeito, com a hegemonia que ainda detém em face de outras paisagens informativas, os media absorvem valores e crenças partilhadas por grande parte do público em relação aos políticos e à política e os reforça por meio de

\footnotetext{
${ }^{112}$ A conferência pode ser consultada no seguinte endereço: http://goo.gl/krtdT1. Consultado a 14 jan. 2015.
} 
narrativas informativas ou ficcionais ${ }^{113}$. Em função de uma reprodução exaustiva por meio da enunciação mediática, essas visões essencialistas da realidade tendem a ser naturalizadas no palco da esfera pública hodierna. Assim, adquirem o estatuto de espinha dorsal do jogo político mediaticamente representado. Essa naturalização é, de resto, traço bastante comum na relação dos cidadãos com a política: tendemos a vê-la como naturalmente vil e degradante, e não como “terreno de salvação”, isto é, de ação coletiva em torno do que é público e, sobretudo, como espaço de gestão de desejos conflitantes ${ }^{114}$. O processo de estereotipia instaurado pelos media encontra, desse modo, menos ancoragem na criação de estereótipos - embora se possa admitir algumas ocorrências, como veremos na análise a seguir - que na absorção, proliferação e, principalmente, na naturalização dessas marcas redutoras da complexidade do mundo, que funcionam como sinais estigmatizantes da generalidade dos agentes públicos.

\footnotetext{
${ }^{113} \mathrm{O}$ entendimento da ideia de processo hegemônico nos media é fruto de uma releitura empreendida do conceito de hegemonia de Gramsci, que pensou o conceito como processo simbólico de exercício do poder, não através do conjunto das instituições políticas e dos órgãos de controle e vigilância, e, sim, através da cultura. Segundo o teórico italiano, a hegemonia não é uma ação partidária, incrustada no aparelho de Estado - diferentemente da ideia de "ideologia" de Althusser —, mas uma ação de classe, ancorada na cultura. A partir desse entendimento é possível pensar os media como instâncias portadoras de um forte poder hegemónico, capaz de fazer passar modelos de entendimento do mundo, muitas vezes oriundos de discursos conservadores. O aspecto central da noção de hegemonia, portanto, [...] "não é o facto de operar forçando as pessoas, contra a sua vontade, a conceder poder àqueles que já são poderosos, mas sim o de funcionar obtendo o consentimento para formas de perceber o mundo que, de facto, fazem sentido" (Hersey, 2004:129).

${ }^{114} \mathrm{Com}$ isso, damos erroneamente à política o mesmo entendimento que Aristóteles deu aos fenómenos naturais, que são baseados pelo "princípio da necessidade", segundo o qual alguma coisa acontece porque tem necessariamente de acontecer. Deixamos, então, de entender a política pela via do "princípio da contingência". Oposto ao primeiro, o princípio da contingência, que abarca vários aspectos da nossa vida, define como contingentes aqueles fenómenos que são de uma maneira, mas que poderiam ser de muitas outras. Ora, como a política se afasta cada vez mais do seu verdadeiro modo de entendimento, - atividade a ser entendida pelo princípio da contingência - passa ser vista numa ótica naturalista, o que, por óbvio, destrói o seu sentido mais nobre de gestão de desejos em conflito. Há, portanto, o efeito ideológico e perverso de enxergarmos a política como terreno naturalmente corrompido, pelo qual os "homens de bem" nada podem fazer, a não ser afastar-se dela.
} 
Observar a relevância assumida pelo público - que contribui para a codificação e atua na descodificação dos enunciados mediáticos - é exercício elucidativo do modus operandi desse processo de estereotipia subjacente à figuração do político nos media. Quer no polo da codificação quer no da descodificação (Hall, 2003), media e público participam ativamente nessa enunciação constituidora de uma mimesis pública, que só faz sentido porque ambos partilham códigos culturalmente enraizados sobre a prática política.

Note-se, porém, que isso não significa concordância do público em relação à mensagem que recebe - e que ajuda a configurar, podendo mesmo refutá-la no quadro de uma "leitura contra-hegemómica" (Hall, 2003) - , mas, antes, que ele domina os signos necessários para o seu acolhimento cognitivo. É exatamente isso que faz funcionar o processo hegemónico mediático: se não houvesse, por exemplo, a partilha simbólica e intersubjetiva de valores e crenças entre a narrativa cinematográfica, que será por nós analisada, e o público, relativamente ao político e à política, muito possivelmente o processo de enunciação ver-se-ia comprometido; ainda que envolto em uma estrutura comunicativa tão poderosa na criação de estereótipos como a da comicidade e do humor na nossa atualidade ${ }^{115}$.

Esse modo de figuração do político na esfera pública mediática de nossos dias também se relaciona com a tendência mediática para adotar uma lógica de infoentretenimento ${ }^{116}$ no tratamento dado a certos temas da política, como forma de atração das audiências, por meio da construção de coberturas jornalísticas e de outros produtos e processos mediáticos que seguem uma liturgia teatralizada, a embrulhar os acontecimentos, situando-os num paradigma novelesco,

\footnotetext{
115 Sobre a criação de estereótipos em produções humorísticas, analisamos a construção da personagem Gina, do Programa Café Central, da RTP 2 (Araújo, 2013).

${ }^{116}$ Discutido por um conjunto de autores, o termo infoentretenimento (infotainment) é geralmente associado à prática que conjuga informação com modos de narração e efeitos poéticos que remetem para o campo do entretenimento.
} 
com regulares traços de espetacularidade e variados efeitos poéticos a compor a construção das narrativas sobre a política. Essa tendência mediática parece enquadrar-se no quadro mais amplo das transformações por que a civilização ocidental mais contemporânea tem passado, aparentemente desejosa de doses cada vez maiores de diversão e espetáculo. É nesse escopo que um autor como Mário Vargas Llosa, na coletânea de ensaios A Civilização do Espetáculo, situa a sua reflexão, para vaticinar, em relação à política, que:

\begin{abstract}
Hoje em dia, em todas as pesquisas de opinião sobre política uma maioria significativa de cidadãos opina que se trata de atividade medíocre e suja, que repele os mais honestos e capazes e recruta sobretudo nulidades e malandros que a veem como uma maneira rápida de enriquecer. [...] A que se deve o facto de o mundo inteiro ter chegado a pensar aquilo que todos os ditadores sempre quiseram inculcar nos povos que subjugam, ou seja, que a política é uma atividade vil? (Llosa, 2013:120-121).
\end{abstract}

A resposta à intrigante pergunta de Vargas Llosa é dada pelo próprio no decurso do mesmo texto, em que imputa, entre outras questões, parcela de responsabilidade aos media e a outras indústrias culturais, incluindo o próprio cinema. Quando essas instâncias criam narrativas que acabam por naturalizar conceções estereotipadas acerca da vida política nacional, dão poucos contributos para a construção de uma democracia plena. Não utilizando exatamente este termo, a reflexão do autor dialoga com o conceito de mediatização da política, que mereceu a atenção de autores como Pierre Bourdieu (1994; 2001; 2011) ou Manuel Castells (2009), ambos preocupados justamente com os efeitos que certas abordagens mediáticas da política terão sobre ela própria no terreno em que institucionalmente se realiza. 
Conquanto a mediatização da política, como a da justiça, seja tema de enorme relevância para qualquer trabalho que deseja entender as representações mediáticas da política, limitamo-nos a fazer referências a autores e textos hoje fundamentais para a compreensão de um fenómeno que não se limita ao universo político - o que terá levado um autor como Eliseo Verón, consciente da presença cada vez maior do fenómeno nas sociedades ocidentais contemporâneas, a dedicar parte significativa do seu trabalho intelectual à procura de pistas para entender a mediatização (Verón, 2014; Hjarvard, 2012; Castells, 2009). Torna-se imperioso ressaltar, de todo modo, em razão do que estamos a discutir, que o processo de estereotipia, que marca uma certa representação da política e dos políticos, parece funcionar como uma das pontas mais problemáticas do conjunto complexo de feixes narrativos, retóricos, discursivos e estilísticos que compõem as processualidades em torno das quais a mediatização da política se manifesta.

\section{Metodologia de análise}

O objeto de análise deste trabalho é o filme de comédia brasileiro, o Candidato Honesto, produzido em 2014, por Roberto Santucci, que conta a história de um político corrupto, candidato à Presidência da República ${ }^{117}$. Parte-se do princípio de que "analisar um filme é sinónimo de decompor esse mesmo filme", o que "implica duas etapas importantes: em primeiro lugar decompor, ou seja, descrever e, em seguida, estabelecer e compreender as relações entre esses elementos decompostos, ou seja, interpretar (Penafrina, 2009: 1).

Ora, tendo em consideração o objetivo deste texto, selecionar-se-á desta narrativa uma categoria que se afigura crucial — a personagem -,

\footnotetext{
${ }^{117}$ O filme está disponível no Youtube em: https://www.youtube.com/watch?v=95I$\mathrm{J}-\mathrm{dKO} 3 \mathrm{No}$
} 
quer porque o título assim o anuncia, já que se centra precisamente num predicado de personagem, quer porque toda a narrativa se desenrola em torno da figura principal: o político João Ernesto Praxedes que tem a ambição de se candidatar à Presidência da República. O objetivo da análise é, então, o de explicar os procedimentos retórico-discursivos de caricaturização da personagem, propondo uma leitura que se compagine com o enquadramento teórico explanado nas partes precedentes. Recorde-se que se parte da desconfiança como valor que deriva da cultura política brasileira e, de certo modo, estrutura a interação dos cidadãos com a política, funcionando aqui como uma metanarrativa, fundamental para a receção e para o estabelecimento de um protocolo de leitura (Motta, 2013) .

Embora não exista uma metodologia universalmente aceite para se proceder à análise, selecionou-se um conjunto de categorias que integram os principais procedimentos de construção de personagens narrativas, contribuindo para a sua figuração. Tendo em conta o género de filme - comédia - e o objetivo da leitura aqui proposta demonstrar como a figura do político é, no espaço público, sujeita a perspetivas de desconfiança -, parece importante cruzar quatro categorias de análise: a caricatura, a tipificação, a figuração e a metalepse.

A caricatura é um conceito correlato do de retrato, que exagera ou distorce certos traços de uma figura, sejam eles físicos, sociais ou comportamentais, com vista a criar efeitos grotescos, criticando e satirizando instituições, classes, grupos, etc. Tem fortes ligações a processos de estereotipia ${ }^{118}$, uma vez que se alimenta de um conjunto de traços - geralmente hiperbolizados - que o público facilmente identifica com os visados. Assim, parece incontornável utilizar, na

\footnotetext{
${ }^{118}$ Ressalve-se a diferença entre tipo e estereótipo: os tipos sociais são conhecidos por partilharem a mesma sociedade e realidade que os leitores, enquanto os estereótipos são imagens pré-concebidas do desconhecido: "Stereotypes are often regarded as the prototypical flat charcter (...) In fiction they differ, according to Dyer, to the extent that social types can appear in almost any kind of plot, while stereotypes carry with them an implicit narrative (Jannidis, 2013:29).
} 
análise que aqui se propõe, uma categoria narrativa subsidiária - o tipo - que se revela particularmente fecunda no que à figuração do protagonista deste filme diz respeito:

\begin{abstract}
(...) o tipo pode ser entendido como personagem-síntese entre o individual e o coletivo, entre o concreto e o abstrato, tendo em vista o intuito de ilustrar de uma forma representativa certas dominantes (...) em conexão estreita com o mundo real com que estabelece uma relação de índole mimética (Reis e
\end{abstract} Lopes, 2003: 411)

Esta definição sumária de tipo, feita pelos autores do Dicionário de Narratologia, aponta para três aspetos que se consideram muito importantes na análise que aqui se constrói: por um lado, o caráter estereotipado das personagens-tipo, capazes de um poder representativo indiscutível; por outro lado, a sua natureza mimética, que implica constantes procedimentos metalépticos com o mundo empírico, dada a conectividade da personagem com o espaço/tempo em que a ficção a coloca, e que tem necessariamente consequências na sua leitura e receção; finalmente, o processo de redução da construção do tipo, que deve privilegiar, sobretudo, um conjunto de atributos facilmente identificáveis pelos leitores.

O conceito de figuração, mais amplo que o de construção, é absolutamente essencial na construção desta análise. Assumindo-se que "a noção de figura não deve ser encarada como mero substituto terminológico do conceito de personagem", a figuração implica uma série de dispositivos de elaboração: "um conjunto de processos constitutivos de entidades ficcionais de feição antropomórfica, conduzindo à individualização de personagens em universos específicos, com os quais interagem" (Reis, 2015: 122). A figuração depende de múltiplos fatores, nomeadamente o medium por que a personagem é veiculada, na medida em que a tecnologia inerente a esse medium implica 
um conjunto de procedimentos e técnicas narrativas específicas que contribuem para a representação da personagem.

A metalepse, conceito oriundo da retórica ${ }^{119}$ mas explorado e adaptado à análise narrativa por Gérard Genette (Genette, 2004), revela-se muito fértil na leitura do fazer personagem em narrativas multimédia, nomeadamente naquelas, como é o caso do filme em questão, que jogam com uma leitura do real, propondo, através de estratégias de veridicção, a crítica a uma classe social, no caso, a classe política. Consiste, segundo o autor francês, em uma transgressão deliberada entre dois universos: o da narração e o da narrativa. Um dos autores responsáveis pela exportação do conceito para outros media que não a literatura, com particular enfoque em produtos multimédia, foi Werner Wolf, para quem a metalepse é "uma transgressão intencional e paradoxal entre mundos ontologicamente distintos e níveis representados em mundos possíveis" (Wolf, 2005: 91). Esta porosidade entre níveis e mundos - o da ficção e o da realidade - pode ser suscitada quer do ponto de vista do produtor da narrativa, quer do ponto de vista do leitor/espectador e pode ter efeitos diversificados: "The former, both as production (author's metalepsis) and as reception (reader immersion), tends toward aesthetic illusion whereas the latter (...) postulates a higher and purely fictitious reality" (Pier, 2014). No caso em apreço - a figuração do protagonista de o Candidato Honesto - o processo metaléptico é feito sobretudo do lado da receção, já que a construção, composição e modelação da personagem exigem uma atitude ativa e colaborativa do espectador, nomeadamente o seu conhecimento da cultura política brasileira e a partilha dos valores que a estruturam. Caberá ao espectador as inferências críticas que nunca são explicitadas ao longo da diegese.

\footnotetext{
119"It is important to bear in mind that although metalepsis has its roots in ancient rhetoric, narrative metalepsis is a recent concept in the history of poetics, with the practice itself, under different denominations, or none at all, reachinh back to antiquity in both literary and visual forms" ( Pier, 2014: s.p.)
} 
Definidas sumariamente as categorias que serão utilizadas nesta análise, importa explicitar a sua operatividade e definir o critérios que presidiram à sua escolha. Tratando-se aqui de uma personagem ficcional - porque integrada numa narrativa fílmica - que protagoniza uma diegese com claros intuitos satíricos, deve procurar-se compreender de que modo ela é construída com um conjunto de atributos que permitem lê-la como símbolo do grupo social alvo de crítica: a classe dos políticos no Brasil. O mesmo é dizer que é fundamental entender a sua dimensão histórico-social, a sua integração geocultural e a sua incidência temática, que a tornam suscetível de fácil identificação pelo espectador. Por outro lado, tendo em consideração o género em questão - um filme humorístico - parece fundamental compreender a consumação do processo caricatural, feito através da hiperbolização de marcas concretas - desde a indumentária, ao discurso ou às relações com outras personagens - que pré-condicionam quer o processo de figuração do protagonista, quer a sua leitura.

\title{
4. A figuração do político no filme $O$ Candidato Honesto
}

\author{
Político: Parece que eu estou tendo negócio de crise de \\ consciência. \\ Assessor: Oh, João, político não tem isso não. \\ Político: O quê, crise? \\ Assessor. Não, consciência! \\ Diálogo extraído do filme O Candidato Honesto (2014, \\ Globo Filmes)
}

A análise de que doravante nos ocuparemos exige que descrevamos, ainda que de forma sucinta, o conteúdo do filme em questão. o Candidato Honesto, com selo da Globo Filmes, conta, como se 
disse, a história de um político candidato à Presidência da República que se encontra em plena campanha eleitoral. Para obter a simpatia do eleitorado, a personagem principal, João Ernesto Praxedes - interpretado pelo ator Rodrigo Hassum - segue à risca as orientações construídas como estratégias de propaganda por especialistas em comunicação política. Nas várias cenas em que aparece em público, o candidato adapta o seu discurso aos desejos da plateia que o ouve, repetindo, em diversas ocasiões, que esta ou aquela comunidade, este ou aquele ideal, serão a sua prioridade tão logo assuma o cargo de presidente. Em outras ocasiões, mostra-se a preocupação dos diretores de campanha com a construção de uma imagem de homem honesto, comprometido com a causa pública e com a defesa da ética e da moralidade na vida política. Em uma das cenas de diálogo entre João Ernesto, candidato do Partido da Ética Democrática Nacional, e o principal assessor de campanha, a personagem teatraliza a frase "Eu quero um Brasil melhor", olhar no horizonte, seguida por uma enorme gargalhada em tom de deboche. Antes de cada aparição pública, assessores sugerem a utilização de camisas amassadas como forma de demonstrar aos eleitores que o candidato tem trabalhado arduamente. Fora dos holofotes mediáticos, para os quais é vendida a imagem de homem humilde e desapegado de grandes luxos, João Ernesto passa os momentos de descanso, ao lado da mulher e dos filhos, numa mansão luxuosa, afastado dos olhos públicos, aonde chega de helicóptero e de onde ensaia discursos fajutos, enquanto enverga uma faixa presidencial de imitação. Cenas assim proliferam ao longo de toda a narrativa, demonstrando o que pode haver de mais gravoso no mundo político: o recurso a práticas antirrepublicanas e antidemocráticas para se chegar ao Poder a qualquer custo.

O ponto nevrálgico da narrativa - aquilo que, em nossa opinião, constitui a estratégica discursiva de maior vitalidade para a construção de uma profunda ironia, com impacto direto na figuração da personagem - é o momento em que, inesperada e involuntariamente, João 
Ernesto perde a capacidade de mentir - algo que os produtores do filme tentam fazer passar como improvável —, após promessa feita à avó que, no leito de morte, apela para que ele adote uma postura de homem honesto na política. Desprovida daquilo que parecia ser condição para a orquestração de estratégias de comunicação política eficazes, visto que, antes desse acontecimento, aparecia em primeiro lugar nas sondagens eleitorais, com expressiva margem de manobra em relação ao seu adversário, a personagem começa a atuar como um ator que resolve descumprir o script previamente estabelecido pelos diretores.

As consequências são retratadas ao longo de quase todo o filme, em cenas que apelam ao riso dos espectadores, por retratarem, de modo profundamente caricatural, o universo da política. A caricatura é aqui construída por meio de estratégias retórico-discursivas que, quer no plano linguístico quer no plano imagético, distorcem e hiperbolizam situações que, conquanto existam no mundo empírico, podem não ser necessariamente a regra. Assim, desde a atuação no âmbito familiar - instado a opinar sobre a roupa da esposa, João Ernesto não titubeia em dizer que ela estava feia e mal vestida - até à maneira de se relacionar com apoiantes de sua campanha - há uma cena em que ele nega o dinheiro proveniente da doação de fiéis, oferecido por um pastor evangélico que, na condição de parlamentar, pleiteava, desde aquele momento, uma vaga de ministro em seu futuro governo - João Ernesto dava sinais de absoluto deslocamento de uma identidade cirurgicamente construída por seus diretores de campanha, em atitudes jamais pensadas, não fosse a perda das capacidades de dissimular e mentir.

Desse modo, existe uma declaração tácita, por parte do enunciador narrativo, de que a dissimulação e a mentira são valores constitutivos do ethos político, que, para ser bem-sucedido, dever-se-ia estruturar em torno deles. Por detrás desse protocolo de leitura possível, subjaz certamente o reforço da desconfiança em relação à política - que, 
na qualidade de valor nuclear da cultura política brasileira, funciona, na narrativa fílmica aqui analisada, como elemento metanarrativo estruturante de um processo de estereotipia que se vai aprofundando à medida em que surgem outros elementos retórico-discursivos de ordem mimética - porém hiperbolizados e, por isso, tendentes a generalizações inoportunas - a aproximar o mundo possível da ficção da dimensão ontológica do mundo empírico. No caso específico de uma narrativa cómica, essa chave de interpretação é acionada e posta em funcionamento no instante mesmo em que o espectador - confrontado, no vídeo que publicita o filme, com a expressão “acredite se puder", em referência à impossibilidade da mentira por parte de um político - sorri, com as cenas que visualiza, demonstrando, pois, que partilha dos valores e das ideias que configuram os códigos interpretativos de leitura da narrativa, sugeridos pelo seu enunciador. Dito de outro modo, o efeito cómico da narrativa fílmica, fundamental para a figuração da personagem, só é conseguido pela confluência de um conjunto de crenças e ideias sobre a classe política que estruturam a interação estabelecida simbolicamente entre enunciador e espectador.

Enredado num esquema de corrupção denominado "mesadinha" - que, metalepticamente, alude ao célebre escândalo do mensalão, desbaratado em 2005, envolvendo o suborno de parlamentares em troca de apoio político no Congresso Nacional - João Ernesto decide confessar a culpa aos jornalistas, aos quais tentou detalhar o modo como o esquema funcionava, mas acabou impedido, porque a direção da campanha resolveu afastá-lo da convivência pública, trancando-o em sua mansão, de forma a travar a queda a pique da sua popularidade. Novamente o enunciador sugere que falar a verdade, em política, é exercício que não se compagina com o objetivo da vitória nas urnas. Em outra cena, confrontado com a pergunta de uma mulher que atua como sua amante, e que lhe pergunta quando ele pretendia dispensá-la, João Ernesto foi taxativo: “Depois das 
eleições". Elucidativo também da estratégia de caricaturização é o momento em que, recorrendo a um pai de santo - figura de raiz africana, muito popular na cultura brasileira -, para tentar reverter a impossibilidade de dizer mentiras, João Ernesto trava um diálogo nestes termos:

Pai de santo: Eu estou acostumado com as criaturas das trevas.

João Ernesto: Ah, o demônio.

Pai de santo: Não, os senadores.

A cena de diálogo é elucidativa do modo como a comicidade inerente ao filme é transformada em elemento nuclear de uma estrutura comunicativa posta ao serviço da depreciação da classe política, como se percebe na associação das expressões "criaturas das trevas" e "senadores". No decorrer da narrativa, outras cenas contribuem para a construção de uma atmosfera caricatural que cola a figura do político ao estatuto de ser inescrupuloso e avesso a quaisquer atitudes éticas, situando-o no campo dos vícios e dos luxos, da imoralidade e da indecência, em que impera um completo desprezo pelas efetivas demandas sociais e pela própria democracia.

Com base na descrição desse elenco de cenas e em consonância com as categorias explanadas na metodologia, parece clara a instauração de um processo de estereotipia que se estrutura em torno do valor da desconfiança e se manifesta por meio da hiperbolização de diferentes traços constitutivos da personagem, contribuindo para a sua figuração e condicionando o campo interpretativo dos espectadores. As cenas que referimos antes dão forma a um conjunto de procedimentos metalépticos que conectam diretamente a narrativa ficcional à dimensão empírica do mundo real, umas das principais estratégias de construção de personagens. Recorde-se, por exemplo, que o lançamento do filme se deu no dia dois de outubro de 2014, quando o Brasil se encontrava em plena campanha eleitoral, a poucos dias para a primeira volta das 
eleições que reelegeriam Dilma Rousseff como Presidente da República, e que elegeriam deputados, senadores e os ocupantes dos poderes executivos e legislativos em todos os estados da Federação. Essa ligação entre a personagem - um ser de papel, como diria Barthes —, com o espaço/tempo em que a ficção a situa é conseguida pelos produtores da narrativa cinematográfica justamente pela mimetização de episódios ainda subsistentes na vida pública brasileira.

Conseguida por meio de um efeito de genericização do real, esses procedimentos caricaturais e metalépticos tendem a retirar à realidade e ao ator retratado a dimensão entrópica que demarca as existências ontológicas, conduzindo a leituras que influenciam diretamente o modo como os cidadãos se relacionam com a política e com os seus representantes. Quando situado, portanto, num contexto de construção de personagens-tipo, mormente daquelas relacionadas com agentes públicos, o efeito perverso desse tipo de estratégia é o de trazer no bojo uma série de estereótipos que, associados mimeticamente ao tipo retratado, reduzem a dimensão humana complexa de qualquer ser humano a um conjunto de traços redutores de identificação, que derivam de um processo arbitrário de seleções, com base em certos critérios, dos quais a ideologia, enquanto sistema de crenças que estrutura a nossa relação com o mundo, faz parte.

Como o que carateriza qualquer processo de estereotipia não é a suposta mentira que transporta, mas a sua tendência para essencializar, hiperbolizar ou reduzir entendimentos sobre culturas, acontecimentos e grupos sociais, o tipo de figuração que analisámos neste texto possui a consequência de estimular o processo já acentuado de depreciação da atividade política nas democracias ocidentais do nosso tempo, associando-se a outras constelações narrativas de mediatização da política que, ficcionais ou não, possuem o mesmo condão de estimular pensamentos segundo os quais o campo político não passa de um universo vil, degradante e alheio a desejos de natureza ética e moral. Assim como a cobertura jornalística da 
corrupção política pode contribuir para minar as instituições e o próprio regime democrático, quando realizada com o recurso a doses expressivas de espetacularidade novelesca, também a representação do ethos político, nos moldes do que observado neste filme, poderá ir na mesma direção (Cunha e Serrano, 2014; Araújo e Prior, 2015).

Outro aspeto que importa salientar é o tipo de relacionamento que a personagem estabelece com a imprensa, representada, no filme, por um jornal, mas sobretudo pela figura da jornalista a quem coube, por determinação do chefe de redação, acompanhar a campanha do candidato. Interessante é que, a despeito da enorme desconfiança de seus colegas de redação em relação ao protagonista, a jornalista, cujo pai havia sido beneficiado por políticas encabeçadas pelo candidato em tempos pretéritos, acreditava na sua honestidade, até ao momento em que, durante uma entrevista, João Ernesto confessa a sua participação no esquema de corrupção sob investigação. O curioso é que, munida de um conteúdo que poderia eliminar de vez as perspetivas do entrevistado de chegar ao poder, a jornalista se comove com a coragem do candidato em dizer a verdade, resolvendo não publicar o que tinha em mãos e pedindo demissão do jornal. Dias depois, no momento em que soube que João Ernesto não iria ao último debate presidencial, deixando o campo livre para o adversário, que agora possuía a maior intenção de votos, a jornalista procura-o na mansão onde estava preso, para convencê-lo a participar. Tendo-o convencido, os dois protagonizam uma verdadeira odisseia para driblar os seguranças e conseguirem chegar a tempo do final do debate. Quando o candidato adversário - prestigiado da plateia pelos antigos assessores de João Ernesto, que, depois de abandoná-lo, apostavam agora na candidatura adversária - já fazia as considerações finais, João Ernesto entra inesperadamente no estúdio de televisão para, numa mensagem aos eleitores, pedir desculpas pela má atuação enquanto homem público e apelar a que eles escolhessem de forma consciente os seus representantes. De seguida, desiste da sua candidatura, deixando o terreno 
livre para o seu adversário, naquele momento, seguidor das mesmas estratégias que tinham alçado João a ocupante do primeiro lugar nas sondagens, antes do episódio que lhe tirou a capacidade de mentir.

Ora, se, por um lado, essa cena parece construir uma leitura preliminar segundo a qual o arrependimento de João Ernesto representaria a ideia que de, na política, verdade, honradez e decência são valores passíveis de existência, o ato de renúncia da personagem pode conduzir o espetador a uma interpretação diferente: é que a desistência da personagem funciona como uma declaração tácita de que, uma vez arrependido e resolvido a agir de forma séria e ética diante da população, o sistema político automaticamente o extirpa, reafirmando-se como campo insuscetivel de ser habitado por quem possui tais qualidades. Aqui, como na maior parte das cenas, temos a construção de uma estratégia que contribui para a figuração de João Ernesto como ser portador de identidade desbotada, em face daquilo que necessariamente the conferiria o estatuto de político de sucesso.

Assumindo-se, em suma, como personagem-síntese entre o individual e o coletivo, na aceção dada por Reis e Lopes (1994) - e configurada em torno de traços estereotipados e, por isso, incapazes de traduzir, no ser retratado no filme, a complexidade e a dimensão plural própria da vida humana - a personagem é colocada no centro de uma narrativa para cujo entendimento interessa a mobilização de uma hermenêutica da suspeição, como diria Ricoeur (1965), e em função da qual o principal efeito social é o de aprofundar o valor da desconfiança desmedida em relação aos políticos e, por tabela, a depreciação da atividade e da prática políticas de nossos dias.

\section{Conclusões}

Este trabalho aprofunda a convicção de vários autores, quer do âmbito dos Estudos Narrativos quer do campo de Estudo dos 
Media, de que a narrativa é um poderoso terreno de exploração empírica a partir do qual é possível compreender a sociedade que nela se encontra retratada. Nesse contexto, a personagem, com toda a sua riqueza significante, emerge como categoria particularmente produtiva, na medida em que a sua figuração transporta sentidos que extrapolam a própria diegese e para cujo entendimento são necessários exercícios hermenêuticos que conjuguem saberes provenientes de diferentes áreas de conhecimento. Essa condição de cognoscibilidade inerente ao estudo da figuração de personagens é ainda mais verdadeira no caso particular das narrativas mediáticas, que funcionam como poderosas fabricantes de mitos contemporâneos, como alertou Barthes já em meados do século passado. De facto, assumindo um claro estatuto semiológico (Hamon, 1977), a personagem, em particular a mediática, acaba por se converter numa estrutura comunicante que veicula ideias, crenças e ideologias, com as quais o leitor/espectador interage.

Como procurámos demonstrar anteriormente, as diferentes estratégias que incidiram na figuração da personagem João Ernesto Praxedes, conferindo-lhe a condição de personagem-tipo, deixam antever um inevitável e poderoso poder representativo da classe política brasileira, que se manifestou mais claramente nas diversas cenas em que o enunciador parecia colocar, no mesmo patamar, os planos da ficção e da realidade, dando à personagem liberdade para transitar metalepticamente entre planos. Esses movimentos de ordem metaléptica, como lhes chamou Genette (2004), são os mais elucidativos da existência de uma sobrevida da personagem, ou seja, da capacidade que esta possui de continuar a existir fora do universo diegético, com diferentes impactos sociais, políticos e culturais, alguns dos quais resumiremos neste espaço conclusivo.

Num país com baixos índices de educação política e uma cultura democrática profundamente ténue, como é o caso brasileiro, a sobrevida da personagem de $O$ Candidato Honesto possui ao menos dois 
efeitos principais: primeiro, o de reacender conceções míopes em relação à política e ao seu funcionamento, por meio da associação de condutas moral e legalmente reprováveis à generalidade da classe política; em segundo lugar, essas mesmas abordagens possuem o condão de interferir, ainda que de modo indireto, na qualidade da relação que o cidadão-espectador-eleitor mantém com os agentes e as instituições que fazem funcionar a política. Essa derradeira influência fica muito evidente quando se percebe que os estereótipos que constroem a imagem da política se ancoram numa cultura ainda hoje marcada por valores e crenças como a alta desconfiança, o clientelismo ou o autoritarismo (Moisés, 1992).

Com efeito, a análise que desenvolvemos é elucidativa do modo como as indústrias culturais constroem constelações semânticas que aprofundam e naturalizam visões estereotipadas sobre o mundo empírico, intensificando, neste caso, o descrédito da atividade política e conduzindo a opinião pública a uma postura próxima da resignação em face de um sistema supostamente apodrecido e tendente a apodrecer quem dele se aproxima. Ao partilhar diariamente narrativas que depreciam a política pela forma como a retratam, o público é envolvido por uma atmosfera narcotizante - expressão de Lazarsfeld e Merton (1978) - que retira de cena qualquer possibilidade de esclarecimento efetivo. Por outro lado, o consequente processo de naturalização das práticas ilícitas como constitutivas do ethos político contemporâneo favorece a criação de climas difusos de indignação na esfera pública, muitas vezes parciais, porque focalizados em discursos condenatórios de partidos e atores políticos específicos. Em outras palavras, se o processo de estereotipia a que o político é submetido contribui para o alargamento dos estereótipos a toda a classe política, também se pode afirmar que, em certas ocasiões, determinados segmentos da política real podem ser mais afetados do que outros pela veiculação de ideias simplistas nos media, de acordo com as quais a corrupção política, por exemplo, 
seria solucionada com a simples extirpação de um ou outro político, desse ou daquele partido do jogo do poder.

Como consequência, é de admitir-se que esse mesmo público, mais ou menos narcotizado, seja levado a afastar-se do ecossistema político, passando a vê-lo unicamente como espaço de perpetração de práticas ilícitas protagonizadas por agentes que poderiam ser substituídos por indivíduos alheios ao universo da política. Basta recordarmos que os momentos de expressivo descontentamento público com as instituições políticas formais são quase sempre marcados pela emergência de movimentos autodenominados de apolíticos e apartidários que procuram deslegitimar o processo político. $\mathrm{O}$ mais terrível e extremo dos exemplos talvez seja o nazismo, que derrubou a República de Weimar, tendo justamente entre os seus argumentos a ideia de que era necessário moralizar a atividade política, numa ação que viesse de fora dela. O mesmo argumento serviu de base para estimular o suicídio de Getúlio Vargas, em 1954 - acusado por Carlos Lacerda, baluarte da direita brasileira, de comandar um "mar de lama" - e, dez anos mais tarde, em 1964, conduziu à derrubada do governo de João Goulart, com a instauração, em seguida, de uma ditadura militar no Brasil. Em nossos dias, o marketing político chega a valer-se do sentimento de desconfiança e de indignação por parte da população, para elaborar estratégias de campanha que depreciam a política: um de muitos exemplos é a letra de um single de campanha do então candidato José Ivo Sartori ao governo do Rio Grande do Sul: "acima da direita, acima da esquerda, acima de qualquer lado (...) o meu partido é o Rio Grande”. Note-se como a estratégia está justamente na tentativa de secundarizar ideologias, como se essas pudessem estar à margem dos processos deliberativos que caracterizam a atividade política.

Em completo descompasso com o que deveria ser o genuíno ethos político, a política aprece representada por João Ernesto Praxedes como como universo propício ao estreitamento do espaço público 
dos direitos e ao alargamento do campo dos interesses particulares dos que assumem cargos e dos que contribuem para a eleição daqueles - caso das grandes empresas - que, por meio de doações de campanha, realizam, na verdade, investimentos mais tarde recompensados pelos eleitos. Estreado num momento eleitoral real, $O$ Candidato Honesto certamente reavivou, na memória coletiva dos eleitores, a ideia de que a política se limita a ser um terreno fértil em atividade vil e degradante, povoado por agentes que antepõem os seus interesses paroquiais e de seus partidos ao interesse público.

Se é verdade, portanto, como alertam alguns autores (Muñoz \& Rospir, 1995), que a política e a democracia hodiernas não existem fora da arena mediática, parece razoável a afirmação de que, ao veicularem tais discursos estereotipados - tendo o valor da desconfiança como substrato narrativo central - os próprios media dão um contributo tácito para a manutenção do status quo, tanto em relação às mazelas que realmente existem na política, quanto no que respeita ao modo com que o cidadão comum se relaciona com ela.

\section{REFERÊNCIAS BIBLIOGRÁFICAS}

ARAÚJO, B. B. (2013). "Discurso mediático e o conceito de estereótipo. A construção da personagem Gina no programa Café Central”. In Silva, A. S. et al. Comunicação Política e Económica. Dimensões cognitivas e discursivas. Braga: Publicações da Universidade Católica Portuguesa, pp. 553-567.

ARAÚJO, B. B.; JORGE, T.M. (2015). "Discurso jornalístico e corrupção política: a construção de uma cobertura legalista e personificada em Veja e CartaCapital". In Verso e Reverso, Unisinos.

BIGNell, J. (1997). Media Semiotics. An Introduction. Manchester: Manchester University Press.

BOURDIEU, P. (1994). "L'emprise du journalisme". In Actes de la recherche en sciences sociales, 101-102, pp. 3-9. 
BOURDIEU, P. (2001). Sobre a televisão. Oeiras: Celta.

BOURDIEU, P. (2011 [1989]). O Poder Simbólico. Lisboa: Difel.

CASTELlS, M. (2009) A Sociedade em Rede.Trad. Roneide Venâncio Majer; vol 1. São Paulo: Ed. Paz e Terra.

CHARAUDEAU, D. (2000). Le discours d'information médiatique. La construction du mirroir social. Paris: Nathan.

CORREIA, J. C. (s/d). "O poder do Jornalismo e a mediatização do espaço público". In: www.bocc.ubi.pt/pag/jcorreia-poder-jornalismo.pdf (Consultado em março de 2013).

ECO, U. (2015). Número Zero. Lisboa: Gradiva.

FULTON, H. Et alii (2005). Narrative and Media. Cambridge: Cambridge University Press.

GEnetTe, G. (2004). Métalepse. Paris: Editions du Seuil.

HALL, S. (2003 [1980]). “Codificação/Descodificação”. In SOVIK, L. (org.), Da Diáspora: Identidades e Mediações Culturais. Belo Horizonte: Humanitas, pp. 387-404.

HAMON, P. (1977). "Pour un statut sémiologique du personnage" in Roland Barthes et alii, Poétique du récit, Paris: Seuils (Points), pp. 115-167.

HEIDBRINK, H. (2010), "Fictional Characters in Literary and Media Studies. A survey of the Research". Eder, J; Jannidis, F.; Schneider, R. (org). Charaters in Fictional Worlds. Understanding Imaginary Beings in Literature, Film, and Other Media. Berlim / Nova Iorque: De Gruyter, pp. 67-110.

HERSEY, J. (2004). Comunicação, Estudos Culturais e Media-conceitos-chave. Trad. Fernanda Oliveira. Lisboa: Quimera.

HJARVARD, S. (2012). "Midiatização: teorizando a mídia como agente de mudança social e cultural”. In Matrizes, v. 5, n. 2, jan-jun. 2012, São Paulo, pp. 53-91.

JANNIDIS, F. (2013). "Character". In The Living Handbook of Narratology http:// www.lhn.uni-hamburg.de/article/character (Consultado a 3 de maio de 2016).

LAZARSFELD, P.; MERTON, P. (1978). "Comunicação de massa, gosto popular e ação social organizada”. In Gabriel Cohn (org.). Comunicação e indústria cultural. São Paulo: Companhia Editora Nacional (texto original de 1948).

LITS, M. (2000). "Information, médias et récit médiatique”. In La question du récit à l'époque de la culture médiatique: mutations et ruptures, Deuxième colloque 
international du CRI, Montréal, 12-15 avril 2000. In: http://migre.me/tURwh. (Consultado a 15-09-2013)

LITS, M. (2008). Du récit au récit médiatique. Bruxelles: De Boeck.

LlOSA, M. (2013). A Civilização do Espetáculo. Trad. Ivone Benedetti. Rio de Janeiro: Objetiva.

MARION, P. (1997). "Narratologie Médiatique et médiagénie des récits". Recherches en Communication, N. ${ }^{\circ}$, pp. 61- 88.

MESQUITA, M. (2003). "Personagem Jornalística: da Narratologia à Deontologia". O Quarto Equívoco. O poder dos media na Sociedade Contemporânea. Coimbra: MinervaCoimbra.

MIGUEL, L. F. (2008). "A mídia e o declínio da confiança na política”. In Sociologias, n. 19, jan-jun, Porto Alegre.

MOISÉS, J. A. (1992) "Democratização e Cultura Política de massas no Brasil". In Lua Nova, n. 26, 5-51.

MOTTA, L. G. (2013). Análise Critica da Narrativa. Brasília: Editora da UnB

MUÑOZ, A.; ROSPIR, J. I. (1995). Comunicación Política. Madrid: Editorial Universitas. PEIXINHO, A. T. (2015). "Procedimentos retórico-narrativos de construção de personagens jornalísticas: o caso do jornal Expresso durante o verão de 2013". Revista de Estudos Literários, N.³. Coimbra: CLP/IUC, pp. 323-347.

PENAFRIA, M. (2009). "Análise de Filmes - conceitos e metodologia(s)". IN: VI Congresso SOPCOM, Abril de 2009 www.bocc.ubi.pt (acedido em dezembro de 2015).

PIER; J. (2014). "Metalepsis". In: The Living Handbook of Narratology http://www. lhn.uni-hamburg.de/article/metalepsis-revised-version-uploaded-12-may-2014\#Genette72 (Consultado a 3 de maio de 2016).

REIS, C. (2015). Pessoas de Livro. Coimbra: IUC.

REIS, C.; LOPES, A. C. (2003). Dicionário de Narratologia. 7. ${ }^{\text {a }}$ ed. Coimbra: Almedina. RICOEUR, P. (1965). De l'interpretation: essai sur Freud. Paris: Seuil, 1965.

TUCHMAN, G. (1980). Making News. A Study in the Construction of Reality. New York and London, The Free Press.

TUCHMAN, G. (1999). “Contando estórias”. In: Traquina, N. (org.). Jornalismo: questões, teorias e estórias. 2. ${ }^{\text {a }}$ ed. Lisboa: Vega, pp. 258-262. 
VALlES CAlATRAVA, J. (2008). Teoría de la narrativa. Una perspectiva sistemática. Madrid: Iberoamericana.

VATTimo, G. (1990). La société transparente. Paris: Desclée de Brouwer.

VERÓN, E. (2014). "Teoria da midiatização: uma perspectiva semioantropológica e algumas de suas consequências”. In Matrizes, v. 8, n. 1, jan-jun. 2014, São Paulo, pp. 13-19.

WOLF, W. (2005). "Metalepsis as a transgeneric and transmedial phenomenon: a case study of the possibilities of 'exporting' narratological concepts". In MEISTER, J. C. (ed.). Narratology beyond literary critiscism: mediality, disciplinarity. Berlin: de Gruyter, pp, 83-107. 